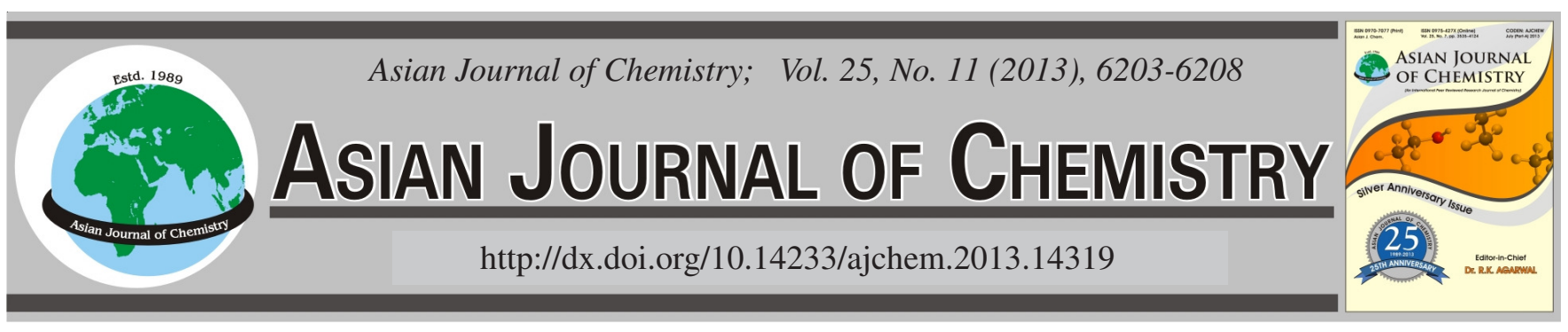

\title{
A Validated Stability Indicating RP-HPLC Method for Nabumetone, Identification and Characterization of Forced Degradation Products of Nabumetone Using LC-MS/MS
}

\author{
SANJAY SAWANT ${ }^{1, *}$ and VIJAYA BARGE ${ }^{2}$
}

${ }^{1}$ Sinhgad Technical Education Society's Smt. Kashibai Navale College of Pharmacy, Kondhwa (Bk.), Pune-411 048, India

${ }^{2}$ PDEA's Seth Govind Raghunath Sable College of Pharmacy, Saswad, Tal-Purandar, Dist-Pune-412 301, India

*Corresponding author: Fax: +91 20 26931322; E-mail: sawant99@ rediffmail.com

(Received: 16 July 2012;

Accepted: 2 May 2013)

AJC-13436

\begin{abstract}
The objective of the present study was to report the stability of novel non-steroidal antiinflammatory drug (NSAID), nabumetone based on the information obtained from forced degradation studies. Nabumetone was subjected to forced hydrolytic, oxidative, photolytic and thermal stress in accordance with the ICH guideline Q1A (R2). The drug showed labiality under only photo-neutral condition by forming a single degradation product. HPLC separation of the drug and the degradation product was achieved on a hypersil gold $\mathrm{C}_{18}$ column (4.6 $\mathrm{mm} \times 250 \mathrm{~mm}, 5 \mu \mathrm{m})$ using an isocratic elution method. The method was extended to LC-MS/MS for characterization of the degradation product and the pathway of decomposition was proposed. Validation of the LC-DAD method was carried out in accordance with ICH guidelines. The method met all required criteria and was applied for analysis of commercially available tablets.
\end{abstract}

Key Words: Nabumetone, Stress degradation studies, Stability indicating assay method, HPLC, LC-MS.

\section{INTRODUCTION}

It is a well known fact that drugs undergo physico-chemical degradation upon storage. Thus, stability testing of a drug under various temperature and humidity conditions is indispensable during the drug development process. In addition, stability testing guidelines issued by International Conference on Harmonization and other international agencies ${ }^{1-4}$ require the reporting, identification and characterization of degradation products (DPs). But, as degradation products generated during storage may be in very low levels (0.1-0.5\%, w/w), stress studies are suggested to generate them in higher amounts ${ }^{5}$. Still sometimes it is very difficult to isolate these species from the stressed mixture due to their low amounts and subject them to spectral analyses for structural information. Tandem mass spectrometry (MSn) and LC coupled with mass spectrometry (LC-MS, LC-MS/MS) are becoming the most versatile techniques for characterization of pharmaceutical degradation products and impurity profiling 6

Nabumetone [4-(6-methoxy-2-naphthyl)butan-2-one] (Fig. 1), is a non-steroidal antiinflammatory drug (NSAID) from the 2,6-disubstituted naphthyl-alkanones class. The drug is metabolized to an active metabolite, 6-methoxy-2-naphthyl acetic acid (6-MNA), which is excreted in urine. Both, drug and metabolite, bind extensively to albumin plasma ${ }^{7}$. Nabumetone, a commercially available drug, is reported as being less aggressive as far as secondary effects are concerned while,

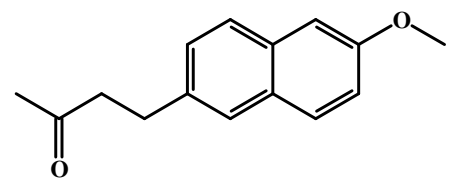

Fig. 1. Chemical structure of nabumetone

at the same time being relatively efficient as an antiinflammatory drug with analgesic properties ${ }^{8-10}$.

Photodegradation of nabumetone in $n$-butanol and aqueous solution was reported by Valero et al ${ }^{11,12}$ by using UV-visible absorption fluorescence and FTIR spectroscopies as well as gas chromatography-mass spectrometry. But neither of the reported method is stability indicating. Recently, Sethi et $a l .{ }^{13}$ have reported stability-indicating RP-UPLC method for the quantitative analysis of nabumetone in tablet dosage form, wherein the drug was found to be stable in all stress conditions and hence it is exclusive of characterization of degradation products under various stress conditions. With this background, it was really necessary to develop and validate a new stability indicating HPLC method which can be transferable to LC-MS for characterization of minute degradation products of nabumetone under various stress conditions. The present manuscript describes the (i) degradation behaviour of nabumetone under hydrolysis (acid, base and neutral), oxidation, photolysis and thermal stress conditions, (ii) optimization of LC conditions to separate the drug and its photoneutral 
degradation product on a reversed-phase $\mathrm{C}_{18}$ column, (iii) method validation, (iv) characterization of degradation product and (v) proposed fragmentation pathway of degradation product using LC-MS/MS.

\section{EXPERIMENTAL}

Nabumetone was supplied by Matrix Pharmaceutical Ltd. (Secundrabad, India). Acetonitrile (HPLC grade) was procured from Merck (Mumbai, India) and used without purification. Analytical reagent grade (AR) hydrochloric acid, sodium hydroxide pellets, hydrogen peroxide solution were purchased from SD Fine Chemicals (Mumbai, India). Ultrapure water was obtained from a water purification unit (Elga Ltd., Bucks, England). Buffer materials and all other chemicals were of AR grade.

An HPLC system used for analysis of stressed samples consisted of binary pump (PU-2080 plus), solvent mixing module (MX-2080-31), multi-wavelength PDA detector (MD2010 plus), interface box (LC-NET II/ADC), rheodyne manual injector (7725i, USA), chrompass data system software 1.8.1.6 version (all from Jasco, Tokyo, Japan) were used. In all studies, separations were achieved on Hypersil Gold $\mathrm{C}_{18}(4.6 \mathrm{~mm} \times$ $250 \mathrm{~mm}, 5 \mu \mathrm{m}$ ) column (Thermo Scientific, Japan). High precision water bath equipped with MV controller (Lab- Hosp Corporation, M.S., India) capable of controlling the temperature with in $\pm 1{ }^{\circ} \mathrm{C}$ was used for generating hydrolytic degradation products. The thermal degradation study was performed using a high precision hot air oven (Narang Scientific Works, New Delhi, India) capable of controlling temperature with in $\pm 2{ }^{\circ} \mathrm{C}$. Photo degradation study was carried out in a photostability chamber (GMP, Thermolab Scientific Equipments Pvt Ltd., Mumbai, India). A pH/ion analyzer (SAB5000, Labindia Instruments Pvt. Ltd., Mumbai, India) was used to check and adjust the $\mathrm{pH}$ of buffer solution. Other small equipments used were sonicator (UCB30, Spectra-lab, Mumbai, India), precision analytical balance (AY220, Shimadzu Corporation, Japan).

The HPLC-MS analyses were carried out on a 500-MS LC Ion Trap Mass spectrophotometer (Varian Inc, USA) in which the HPLC part comprised of an auto sampler (410, Prostar), solvent delivery module (210, Prostar), column valve module (500, Prostar), PDA Detector (355, Prostar), fraction collector (710, Prostar). MS (500-MS IT) system consisted of direct infusion mass with positive as well as negative APCI ionization (+APCI and -APCI) modes, mass ranging from 50$2000 \mathrm{~m} / \mathrm{z}$. The system was controlled by 500-MS Workstation software. In LC-MS studies the separation was carried out on Hypersil Gold $(4.6 \mathrm{~mm} \times 250 \mathrm{~mm}, 5 \mu \mathrm{m})$.

Stress decomposition studies: Forced degradation studies of bulk drug and drug formulation included appropriate solid state and solution state stress conditions in accordance with regulatory guidelines. The stressors, choice of their concen- tration and preparation of samples were based on guidelines in the publication ${ }^{14}$. As the drug was insoluble in water, it was dissolved in a mixture of acetonitrile and water in a ratio of $60: 40(\mathrm{v} / \mathrm{v})$ to a final concentration of $2 \mathrm{mg} \mathrm{mL}^{-1}$. The stock was diluted 50:50 (v/v) with the stressor (e.g., $\mathrm{HCl}, \mathrm{NaOH}$, $\mathrm{H}_{2} \mathrm{O}_{2}$ and water, etc.). All hydrolytic studies were conducted at $80{ }^{\circ} \mathrm{C}$. The oxidative study was carried out in $30 \%$ (v/v) $\mathrm{H}_{2} \mathrm{O}_{2}$ at room temperature. For thermal stress testing, the drug was sealed in glass vials and placed in a thermostatic block at $50{ }^{\circ} \mathrm{C}$ for 21 days. Photolytic studies on the drug in the solid and solution state were carried out by exposure to a combination of UV and fluorescent lamps in a photostability chamber set at accelerated conditions of temperature and humidity $\left(40^{\circ} \mathrm{C} /\right.$ $75 \% \mathrm{RH}$ ). Parallel blank set was kept in dark for comparison. After subjecting to stress, samples were withdrawn at suitable time interval. The optimized stressed conditions are enlisted in Table-1.

Sample preparation for HPLC and LC-MS analysis: The stressed samples of acid and base hydrolysis were neutralized with $\mathrm{NaOH}$ and $\mathrm{HCl}$, respectively to obtain 500 $\mu \mathrm{g} \mathrm{mL} \mathrm{L}^{-1}$ solutions. Neutral hydrolysis, thermal and photolytic samples were diluted with mobile phase to obtain $500 \mu \mathrm{g} \mathrm{mL}{ }^{-1}$ solutions. The oxidative stress sample was diluted with mobile phase to obtain $100 \mu \mathrm{g} \mathrm{mL} \mathrm{m}^{-1}$ solution. All the prepared samples were passed through $0.45 \mu \mathrm{m}$ membrane filter before HPLC and LC-MS analyses.

\section{RESULTS AND DISCUSSION}

Optimization of LC-MS conditions: The main aim of this work was to separate nabumetone and its degradation product. During the optimization process, preliminary experiments were carried out on HPLC using Hypersil Gold C-18 column $(4.6 \times 250 \mathrm{~mm}, 5 \mu \mathrm{m})$. For mobile phase selection, several conditions with various mobile phases like methanol/ water and acetonitrile/water in different proportions were tried in an isocratic mode. The peaks corresponding to drug and degradation product did not resolve completely and tailing was noticed. To get acceptable separation between the drug and its degradation product, potassium dihydrogen ortho phosphate buffer was used. Further studies were carried out using varied proportions of acetonitrile (A) and potassium dihydrogen ortho phosphate buffer (B). The $\mathrm{pH}$ of the buffer, flow rate and composition of the mobile phase were systematically varied to optimize the method. To detect drug and degradation product with sufficient peak intensity, the wavelength $229 \mathrm{~nm}$ was selected. Fig. 2 shows UV absorbance spectra of drug and degradation product using a PDA detector. Finally, we achieved good resolution of peaks with acceptable shape with the mobile phase consisting of A and $\mathrm{B}(\mathrm{pH} 4.0 ; 0.01 \mathrm{M})(60: 40, \mathrm{v} / \mathrm{v})$, in an isocratic mode. The flow rate $1 \mathrm{~mL} \mathrm{~min}^{-1}$, column temperature $25^{\circ} \mathrm{C}$, wavelength of $229 \mathrm{~nm}$ and injection volume $20 \mu \mathrm{L}$

TABLE 1

OPTIMIZED STRESS CONDITIONS FOR THE DRUG

\begin{tabular}{|c|c|c|c|c|c|c|c|c|c|}
\hline \multirow[t]{2}{*}{ Stressors } & \multicolumn{3}{|c|}{ Hydrolytic at $50^{\circ} \mathrm{C}$} & \multirow{2}{*}{$\begin{array}{l}\text { Oxidative } \\
\text { at RT }\end{array}$} & \multicolumn{4}{|c|}{$\begin{array}{l}\text { Photolytic at } 1.2 \times 10^{6} \text { Lux fluorescent and } \\
200 \mathrm{~W} \mathrm{~h} / \mathrm{m}^{2} \mathrm{UV} \text { light at } 40^{\circ} \mathrm{C} / 75 \% \mathrm{RH} \\
\end{array}$} & \multirow{2}{*}{$\begin{array}{l}\text { Thermal at } \\
50^{\circ} \mathrm{C}\end{array}$} \\
\hline & Acid & Neutral & Base & & Acid & Neutral & Base & Solid & \\
\hline Concentration of stressor & $2 \mathrm{~N} \mathrm{HCl}$ & $\mathrm{H}_{2} \mathrm{O}$ & $2 \mathrm{~N} \mathrm{NaOH}$ & $30 \% \mathrm{H}_{2} \mathrm{O}_{2}$ & $0.2 \mathrm{~N} \mathrm{HCl}$ & $\mathrm{H}_{2} \mathrm{O}$ & $0.2 \mathrm{~N} \mathrm{NaOH}$ & - & - \\
\hline Duration & $4 \mathrm{~d}$ & $4 \mathrm{~d}$ & $4 \mathrm{~d}$ & $2 d$ & $13 \mathrm{~d}$ & $13 d$ & $13 \mathrm{~d}$ & $13 \mathrm{~d}$ & $21 \mathrm{~d}$ \\
\hline
\end{tabular}




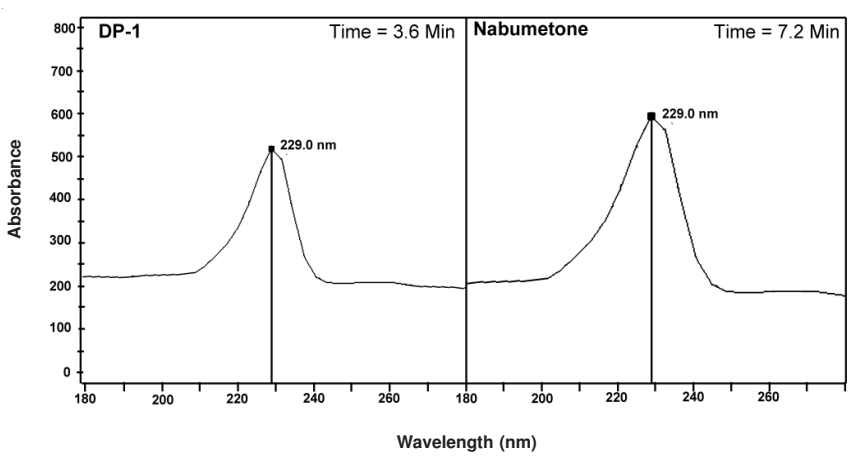

Fig. 2. PDA absorbance spectra of DP-1 and nabumetone

were found to be suitable to achieve the separation of nabumetone and its degradation product (Fig. 3A). As the above mentioned, $\mathrm{C}-18$ column gave good resolution of drug and its degradation product, the same column was used for HPLC analyses. The advantage of the method was simple and rapid. Validation of the optimized LC method was done with respect to various parameters outlined in $\mathrm{ICH}$ guideline ${ }^{15}$ and was extended to LC-MS/MS studies. The chromatographic conditions used for LC-MS analyses were the same as that for LC-PDA analyses, except that the buffer component B was replaced by $0.01 \mathrm{M}$ ammonium acetate of the same $\mathrm{PH}$ and injection volume was $10 \mu \mathrm{L}$. Fig. 3B shows LC-MS chromatogram obtained using mobile phase containing ammonium acetate buffer, wherein retention time of drug and degradation product was not affected.

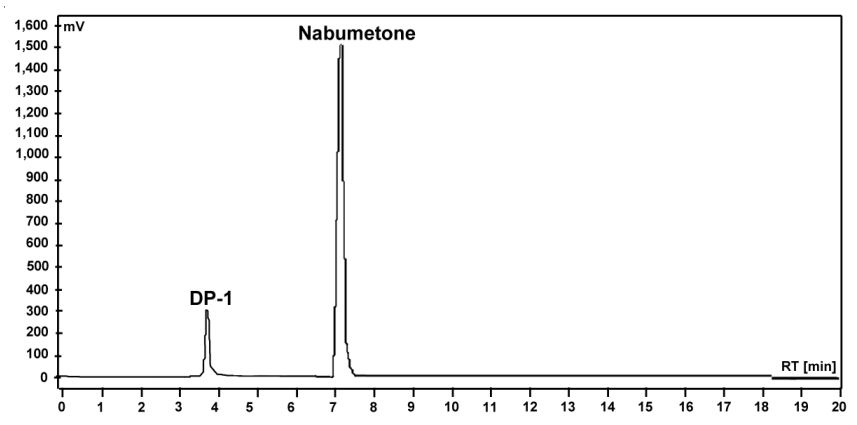

(A)

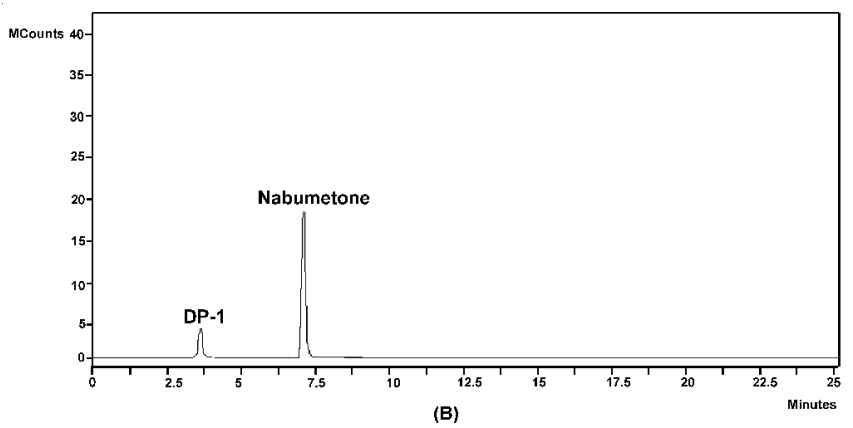

Fig. 3. LC-PDA chromatogram (A) and LC-MS chromatogram (B) showing separation of drug and DP-1 in photoneutral stressed sample

LC-MS/MS studies were carried out in + APCI ionization mode in the mass range of 50-2000 amu. High purity helium was used as carrier gas and nitrogen was used as nebulizer. Mass parameters were optimized to the following values: $\mathrm{R}_{\mathrm{f}}$ loading: $80 \%$; capillary voltage, $80 \mathrm{~V}$; syringe volume, 250 $\mu \mathrm{L}$; spray chamber temperature, $50{ }^{\circ} \mathrm{C}$; nebulizer pressure, 35 psi; drying gas temperature, $300{ }^{\circ} \mathrm{C}$; drying gas pressure, 10 psi; vaporizer gas temperature, $350^{\circ} \mathrm{C}$; vaporizer gas pressure, $20 \mathrm{psi}$; spray shield voltage $( \pm), \pm 600.0 \mathrm{~V}$.

Specificity: Specificity is the ability of the analytical method to measure the analyte concentration accurately in presence of all potential degradation products. Specificity of the method towards the drug was studied by determination of purity for drug peak in stressed sample using a PDA detector. The study of resolution factor of the drug peak from the nearest resolving degradation product was also done. Both drug and degradation product peaks were found to be pure from peak purity data. Also, the resolution factor for the drug from degradation peak was greater than 3 .

Linearity: Linearity test solutions were prepared from stock solution at seven concentration levels of analyte $(3,6$, $\left.10,20,30,40,50,60,70,80 \mu \mathrm{g} \mathrm{mL}^{-1}\right)$. The peak area versus concentration data was performed by least squares linear regression analysis. The calibration curve was drawn by plotting nabumetone average area for triplicate injections and the concentration expressed as a percentage. Linearity was checked over the same concentration range for three consecutive days. Good linearity was observed in the concentration range from $3-80 \mu \mathrm{g} \mathrm{mL}^{-1}$ of nabumetone. The data is subjected to statistical analysis using a linear regression model; the linear regression equation and correlation coefficient $\left(\mathrm{r}^{2}\right)$ were $\mathrm{y}=$ $4.916 x-0.743$ and 0.999 , respectively. These results indicate good linearity. The LOD and LOQ for nabumetone were estimated at a signal-to-noise ratio of 3:1 and10:1, respectively. The LOD and LOQ were 0.10 and $0.31 \mu \mathrm{g} \mathrm{mL} \mathrm{L}^{-1}$, respectively.

Precision: Precision of the method was verified by repeatability and intermediate precision studies. Repeatability studies were performed by analyses of three different concentrations of the drug in hexaplicate on the same day. Intermediate precision of the method was checked by repeating the studies on three different days. Additionally, the developed HPLC method was checked through separation studies on the mixture of reaction solutions on a different chromatographic system on a different day. The results of repeatability and intermediate precision experiments are shown in Table-2. The developed method was found to be precise as the RSD values for repeatability and intermediate precision studies were less than 0.186 and 0.746 , respectively. Separation of the drug and degradation product in stressed sample was found to be similar when analyses were performed on a different chromatographic system on a different day.

TABLE-2

INTRA-DAY AND INTER-DAY PRECISION STUDIES

\begin{tabular}{|c|c|c|}
\hline \multirow{2}{*}{$\begin{array}{l}\text { Concentration } \\
\text { taken }\left(\mu \mathrm{g} \mathrm{mL}^{-1}\right)\end{array}$} & \multicolumn{2}{|c|}{ Measured concentration $\left(\mu \mathrm{g} \mathrm{mL} L^{-1}\right) \pm$ S.D., RSD $(\%)$} \\
\hline & $\begin{array}{l}\text { Intra-day precision } \\
\qquad(n=6)\end{array}$ & $\begin{array}{c}\text { Inter-day precision } \\
\qquad(n=3)\end{array}$ \\
\hline 30 & $30.28 \pm 0.037,0.123$ & $30.31 \pm 0.060,0.202$ \\
\hline 40 & $40.91 \pm 0.069,0.169$ & $40.90 \pm 0.305,0.746$ \\
\hline 50 & $49.03 \pm 0.091,0.186$ & $49.01 \pm 0.088,0.181$ \\
\hline
\end{tabular}

Accuracy: Accuracy of the method was assessed by spiking a mixture of stressed samples with three known concentrations of nabumetone, viz., 10, 20 and $30 \mu \mathrm{g} / \mathrm{mL}$, in triplicate and 
then determining the percent recovery of the added drug. The percentage of added drug obtained from difference between peak areas of unfortified and fortified samples of nabumetone. As shown in Table-3, good recoveries (99.66 to $99.96 \%$ ) of the spiked drugs were obtained at each added concentration, indicating that the method was accurate.

\begin{tabular}{ccc} 
TABLE-3 \\
& RECOVERY STUDIES \\
\hline $\begin{array}{c}\text { Spiked conc. } \\
\left(\mu \mathrm{g} \mathrm{mL}^{-1}\right)\end{array}$ & $\begin{array}{c}\text { Measured conc. }\left(\mu \mathrm{mL}^{-1}\right) \\
\pm \text { SD, RSD }(\%)\end{array}$ & $\begin{array}{c}\text { Recovery } \\
(\%)\end{array}$ \\
\hline 10 & $9.96 \pm 0.251,0.252$ & 99.66 \\
20 & $19.99 \pm 0.03,0.15$ & 99.96 \\
30 & $29.96 \pm 0.035,0.116$ & 99.88 \\
\hline
\end{tabular}

Robustness: To determine the robustness of the method, experimental conditions were purposely altered. Three parameters selected were flow rate, composition of mobile phase and solvent from different lots. The mobile phase flow rate was $1 \mathrm{~mL} / \mathrm{min}$. This was changed to 1.1 and $0.9 \mathrm{ml} / \mathrm{min}$ and the effect was studied. The effect of mobile phase composition was studied by use of acetonitrile and potassium dihydrogen ortho phosphate buffer ( $\mathrm{pH} 4.0 ; 0.01 \mathrm{M}$ ) in ratio of 59:41 and $61: 39(\mathrm{v} / \mathrm{v})$. Also acetonitrile of different lots from same manufacturer was used. When the effect of altering one set of conditions was tested, the other conditions were held constant at the optimum values. Thus, replicate injections $(n=3)$ of standard solution were performed (100 ppm) under small changes of three chromatographic parameters. In all the deliberately varied chromatographic conditions, no significant change in retention time and tailing factor of nabumetone was observed (Table-4).

\begin{tabular}{|c|c|c|c|}
\hline \multicolumn{4}{|c|}{$\begin{array}{c}\text { TABLE-4 } \\
\text { ROBUSTNESS STUDIES }\end{array}$} \\
\hline \multicolumn{4}{|c|}{ Chromatographic changes } \\
\hline Factor $^{\mathrm{a}}$ & Level & $\mathrm{RT}^{\mathrm{b}}$ & $T_{f}^{c}$ \\
\hline \multicolumn{4}{|l|}{ A: Flow rate $(\mathrm{mL} / \mathrm{min})$} \\
\hline 0.9 & -1 & 7.27 & 1.22 \\
\hline 1.0 & 0 & 7.2 & 1.19 \\
\hline 1.1 & 1 & 6.95 & 1.15 \\
\hline Mean \pm S. D. $(n=3)$ & & $7.14 \pm 0.16$ & $1.18 \pm 0.03$ \\
\hline \multicolumn{4}{|c|}{$\begin{array}{l}\text { B: Percentage of acetonitrile } \\
\text { in the mobile phase }(v / v)\end{array}$} \\
\hline 59 & -1 & 7.24 & 1.23 \\
\hline 60 & 0 & 7.2 & 1.19 \\
\hline 61 & 1 & 7.0 & 1.24 \\
\hline Mean \pm S. D. $(n=3)$ & & $7.14 \pm 0.12$ & $1.22 \pm 0.02$ \\
\hline \multicolumn{4}{|c|}{ C: Solvents of different lots } \\
\hline First lot & & 7.25 & 1.22 \\
\hline Second lot & & 7.26 & 1.24 \\
\hline Mean \pm S.D. $(n=3)$ & & $7.25 \pm 0.007$ & $1.23 \pm 0.014$ \\
\hline
\end{tabular}

System suitability test: The system suitability parameters with respect to theoretical plates, capacity factor, resolution factor, tailing factor were calculated and are given in Table-5. It could be seen from table that all the peaks were well resolved.

\begin{tabular}{|c|c|c|c|c|c|}
\hline \multicolumn{6}{|c|}{$\begin{array}{c}\text { TABLE-5 }^{\text {TABL }} \\
\text { HPLC SYSTEM SUITABILITY PARAMETERS }^{\mathrm{a}}\end{array}$} \\
\hline Code & RT & $\mathrm{k}$ & $\mathrm{R}_{\mathrm{s}}$ & $\mathrm{N}$ & $\mathrm{T}_{\mathrm{f}}$ \\
\hline DP-1 & 3.6 & 0.8 & 9.0 & 3580 & 1.03 \\
\hline Nabumetone & 7.2 & 2.6 & 9.0 & 8520 & 1.19 \\
\hline
\end{tabular}

Degradation behaviour: The drug degraded into DP-1 under photoneutral condition. The extent of degradation was $24 \%$ under this condition. The chromatogram of the mixture of drug and degraded sample is shown in Fig. 3A. The drug was stable under all other stress conditions, including heating in acid, base, water, oxidation, on exposure of acid and base solutions to light, photoexposure of solid drug and dry heating at $50^{\circ} \mathrm{C}$.

Study of the stability of commercial tablets: The assay content of nabumetone, commercially available marketed formulation was analyzed by the proposed method after exposure to accelerated storage condition (i.e. $40^{\circ} \mathrm{C} / 75 \% \mathrm{RH}$ ). The peak at retention time $7.2 \mathrm{~min}$ for the drug was observed in the chromatogram of the drug samples extracted from tablets and no additional peak was found (Fig. 4). Experimental results of the amount of nabumetone in tablets, expressed as percentage of label claim were in good agreement with the label claims thereby suggesting that there is no interference from any excipients, which are normally present in tablets and packaging material is of good quality (Table-6).

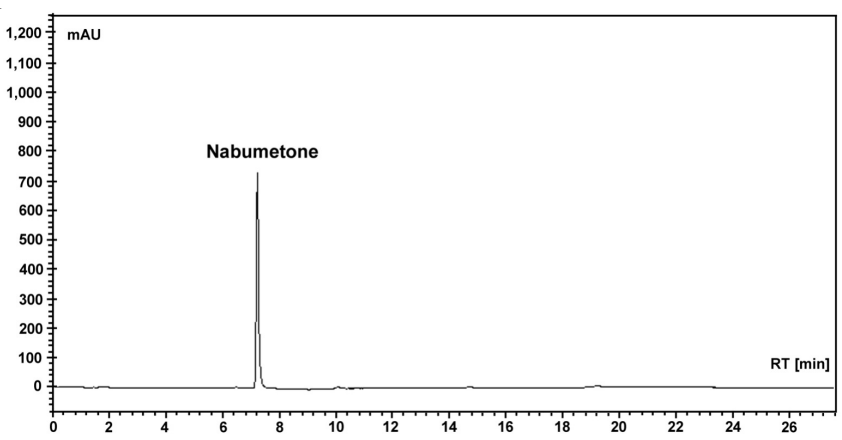

Fig. 4. Chromatogram of marketed formulation

\section{Characterization of nabumetone and its degradation products by LC-MS/MS experiments}

Mass fragmentation pathway of the drug: The mass fragmentation pathway of the drug was established from results of LC/APCI/MS in positive mode and MS/MS analysis using optimized mass parameters. The APCI/MS of $[\mathrm{M}+\mathrm{H}]^{+}$ion at

TABLE-6

STUDY OF STABILITY OF COMMERCIAL TABLETS $(\mathrm{N}=3)$

\begin{tabular}{lccccc}
\hline Marketed formulation & Duration & Taken $\left(\mu \mathrm{g} \mathrm{mL}^{-1}\right)$ & Found $\left.(\mu \mathrm{g} \mathrm{mL})^{-1}\right)$ & Label claim \% $( \pm$ SD $)$ & RSD $(\%)$ \\
\hline Nabuflam 500 mg & 1 month & 50 & 49.06 & $98.00 \pm 0.127$ & 0.129 \\
Micro Labs Ltd., & 2 months & 50 & 49.05 & $98.10 \pm 0.172$ & 0.175 \\
Bangalore & 3 months & 50 & 49.05 & $98.14 \pm 0.140$ & 0.142 \\
\hline
\end{tabular}


$\mathrm{m} / \mathrm{z} 229.1$ shows abundant fragment ions at $\mathrm{m} / \mathrm{z} 227.1$ (loss of $2 \mathrm{H}^{+}$from $\mathrm{m} / \mathrm{z} 229.1$ ), $\mathrm{m} / \mathrm{z} 211.1$ (first loss of $-\mathrm{CH}_{3}, 2 \mathrm{H}^{+}$from $\mathrm{m} / \mathrm{z} 229.1$ followed by loss of $\mathrm{H}^{+}$from $\mathrm{m} / \mathrm{z} 212.1$ ) (Fig. 5 , Scheme-I). APCI/MS/MS of m/z 211 shows abundant fragment ions at $\mathrm{m} / \mathrm{z} 209.1$ (loss of $2 \mathrm{H}^{+}$from $\mathrm{m} / \mathrm{z} 211$ ), $\mathrm{m} / \mathrm{z} 179.1$ (loss of $-\mathrm{OCH}_{3}, \mathrm{H}^{+}$from m/z 211). APCI/MS/MS of m/z 227 shows abundant fragment ions at $\mathrm{m} / \mathrm{z} 209.1$ (loss of $-\mathrm{CH}_{3}, 3 \mathrm{H}^{+}$ from $\mathrm{m} / \mathrm{z} 227$ ), $\mathrm{m} / \mathrm{z} 171.1$ (loss of first $-\mathrm{COCH}_{3}, \mathrm{CH}_{3}$ from $\mathrm{m} / \mathrm{z} 227$ followed by addition of $2 \mathrm{H}^{+}$) (Fig. 6, Scheme-I).

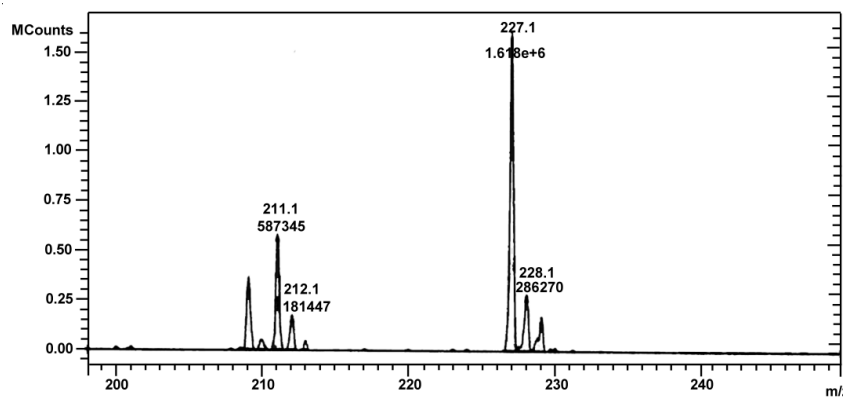

(A)

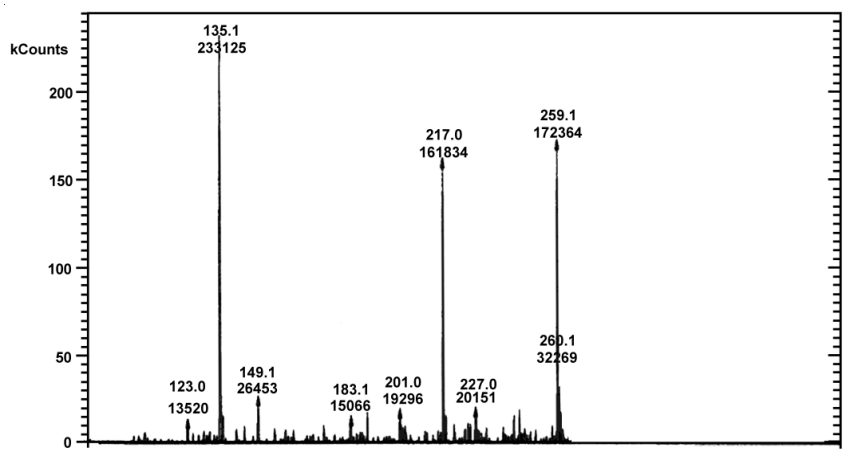

(B)

Fig. 5. LC/MS spectra (A,B) of nabumetone and DP-1, respectively, in + APCI mode

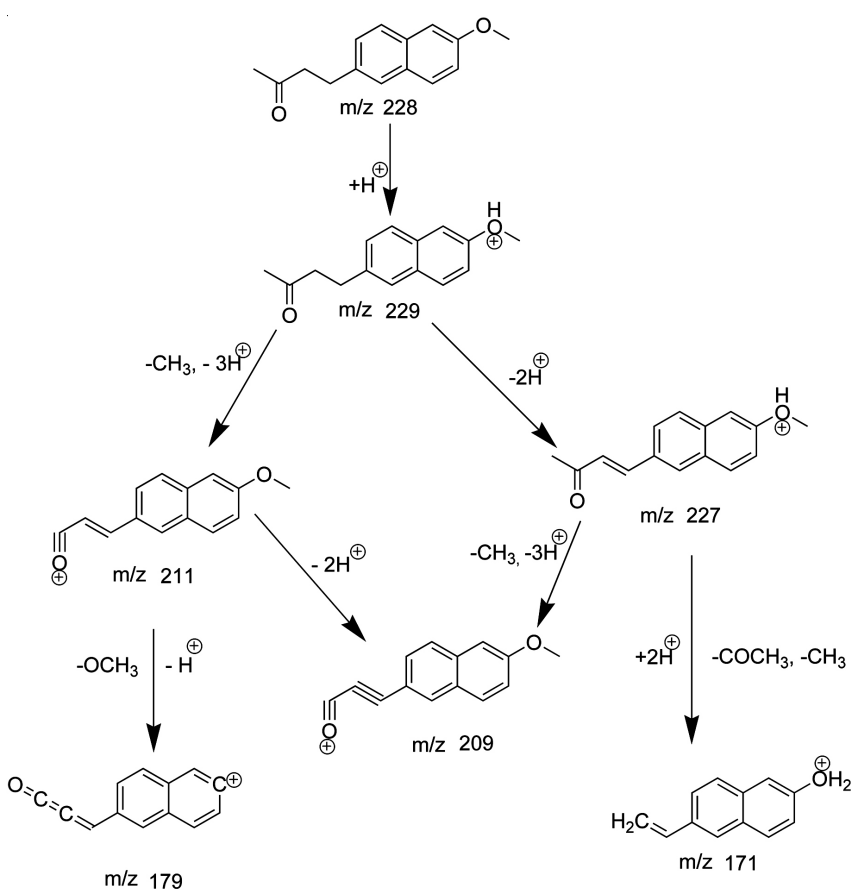

Scheme-I: Mass fragmentation pattern of nabumetone
Postulated structure of the degradation product (DP-1) $(\mathbf{m} / \mathbf{z} 259)$ : The product was obtained due to addition of HCHO formed upon exposure of drug solution in acetonitrile to UV and visible light. The APCI-MS of $\mathrm{m} / \mathrm{z} 259$ in positive mode shows abundant fragment ion at $\mathrm{m} / \mathrm{z} 217.0$ (loss of $\mathrm{CH}_{2}=\mathrm{C}=\mathrm{O}$ from $\mathrm{m} / \mathrm{z} 259.1$ ) and less abundance ion at $\mathrm{m} / \mathrm{z} 227.0$ (loss of $\mathrm{CH}_{3} \mathrm{OH}$ from $\mathrm{m} / \mathrm{z}$ 259.1) (Fig. 5). The APCI-MS/MS of $\mathrm{m} / \mathrm{z}$ 259 shows abundant fragment ions at $\mathrm{m} / \mathrm{z} 217.1$ (loss of $\mathrm{CH}_{2}=\mathrm{C}=\mathrm{O}$ from $\mathrm{m} / \mathrm{z} 259.1$ ), $\mathrm{m} / \mathrm{z} 241.1$ (loss of $\mathrm{H}_{2} \mathrm{O}$ from $\mathrm{m} / \mathrm{z}$ 259.1), m/z 199.1 (loss of $\mathrm{CH}_{2}=\mathrm{C}=\mathrm{O}, \mathrm{H}_{2} \mathrm{O}$ from $\mathrm{m} / \mathrm{z} 259.1$ ), $\mathrm{m} / \mathrm{z} 173.1$ (loss of $\mathrm{C}_{2} \mathrm{H}_{2}$ from $\mathrm{m} / \mathrm{z}$ 199.1) (Fig. 6). The proposed mechanism and fragmentation pattern is shown in Scheme II.

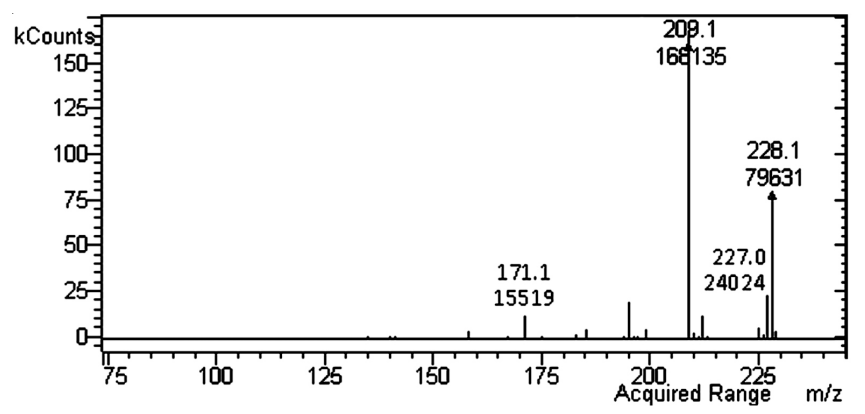

(C)

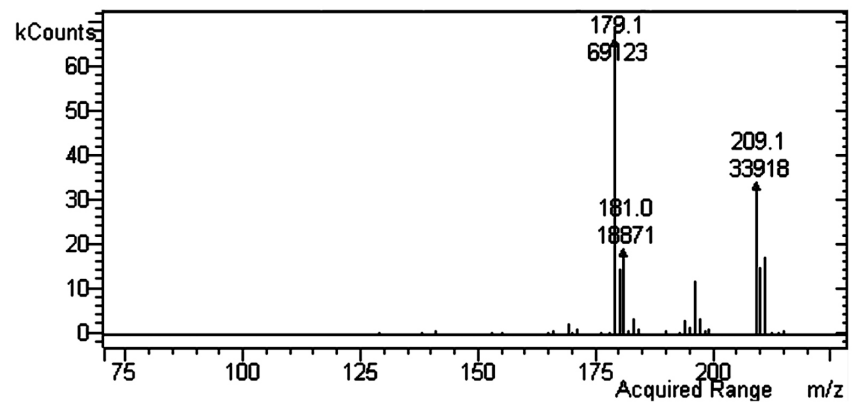

(D)

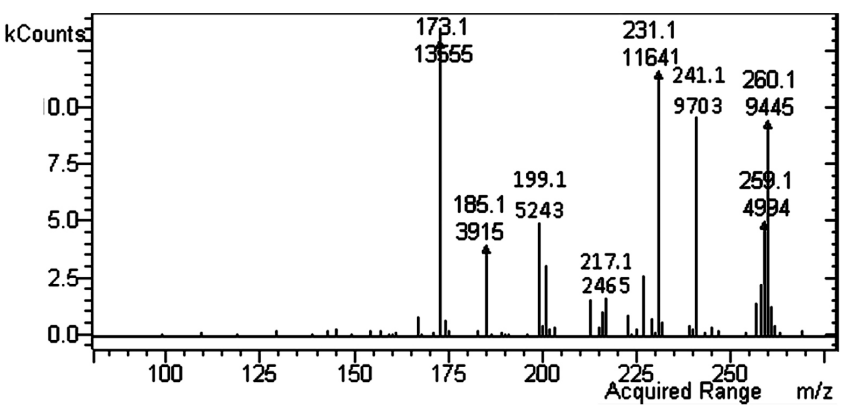

(E)

Fig. 6. MS/MS spectra (C, D, E) of fragment ions at m/z 227, m/z 211 and DP-1, respectively, in +APCI mode

\section{Conclusion}

Stress degradation studies on nabumetone, carried out according to ICH guidelines, provided information regarding degradation behaviour of the drug. The drug was susceptible to only photoneutral degradation, whereas it was stable in all other conditions. One degradation product [DP-1] was formed in photoneutral condition and was separated in a single run by an isocratic LC-DAD method. The method proved to be simple, accurate, precise, specific and robust. It was successfully 


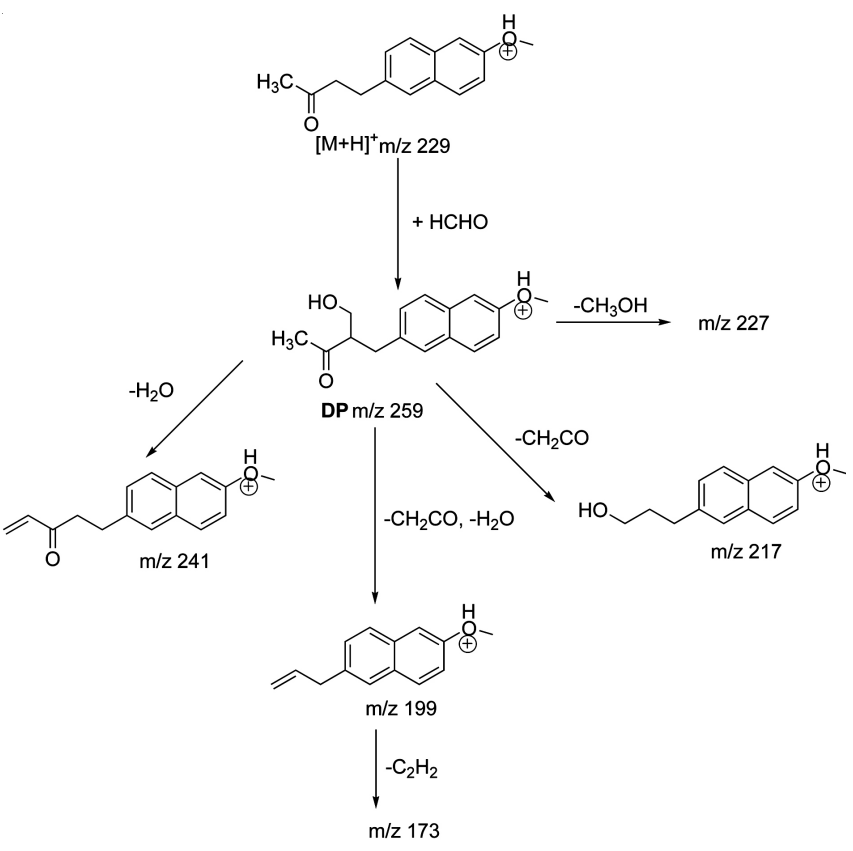

Scheme-II: Proposed fragmentation for DP-1

employed for the analysis of marketed formulation stored for three months under accelerated conditions of temperature and humidity. The product DP-1 was characterized with the help of LC-MS/MS data and comparison of the same to that for the drug. The complete degradation pathway of the drug and mechanism of the formation of DP-1 and its fragmentation is proposed in Scheme-I and II. The proposed method can thus be used for routine analysis, quality control and for studies of pharmaceutical tablets containing this drug.

\section{ACKNOWLEDGEMENTS}

The authors acknowledged Dr. S.Y. Gabhe, Professor, Department of Pharmaceutical Chemistry, Poona College of Pharmacy, Pune for technical discussions. The authors also thank Dr. Ashok V. Bhosale, Principal, PDEA's S.G.R.S. College of Pharmacy, Saswad for providing necessary facilities.

\section{REFERENCES}

1. ICH, Q1A (R2)-Stability Testing of New Drug Substances and Products, International Conference on Harmonization, IFPMA, Geneva (2003).

2. WHO-Draft Stability Testing of Active Pharmaceutical Ingredients and Pharmaceutical Products, World Health Organization, Geneva (2007).

3. CPMP-Note for Guidance on Stability Testing: Stability Testing of Existing Active Substances and Related Finished Products, Committee for Proprietary Medicinal Products, EMEA, London (2002).

4. TPD-Guidance for Industry Stability Testing of Existing Drug Substances and Products, Therapeutic Products Directorate, Health Canada, Ottawa, ON (2003).

5. M. Bakshi and S. Singh, J. Pharm. Biomed. Anal., 28, 1011 (2002).

6. Y. Wu, Biomed. Chromatogr., 14, 384 (2000).

7. N.M. Davies, Clin. Pharmacokinet., 33, 403 (1997).

8. O.R. Carryl and R.S. Spangler, Scand. J. Rheumatol., 24, 336 (1995).

9. G.B.F. Porro, M. Montrone, P.I. Caruso and V. Imbesi, Am. J. Gastroenterol., 90, 1485 (1995).

10. W. Bensen and A. Zizzo, Can. Family Physician, 44, 101 (1998).

11. M. Valero and S.M. Costa, J. Photochem. Photobiol. A, 157, 93 (2003).

12. M. Valero, J. Photochem. Photobiol. A, 163, 159 (2004).

13. N. Sethi, A. Anand, K.K. Chandrul, G. Jain and K.S. Srinivas, J. Chromatogr. Sci., 50, 85 (2012).

14. S. Singh and M. Bakshi, Pharm. Technol., pp. 1-14 (2000).

15. ICH, Q2 (R1)-Validation of Analytical Procedures- Text and Methodology, International Conference on Harmonization Geneva, Switzerland (2005). 